\title{
Sobre Walter George Durst e a arte de roteirizar
}

$\frac{\text { ANNA MaRIa BaLOGH E ANTÔNIO AdAMI }}{\text { Pós-Graduação em Comunicação - UNIP }}$ 


\section{Resumo}

$\mathrm{O}$ artigo faz a recolecção de alguns dos principais conceitos e observações de Walter George Durst no tocante à arte de roteirizar, da qual foi um dos maiores representantes na TV brasileira, nos diferentes eventos e entrevistas que se teve oportunidade de realizar em diversos contatos com o roteirista.

Palavras-chave

roteirização, adaptações, literatura, televisão

\section{Abstract}

The article is a recolection of the concepts of one of the most outstanding professionals of Brazilian television about his work as a script-writer, which were obtained during enterviews and academic events in different contacts maintained with the artist.

\section{Key words}

screen-writing, adaptations, literature, television 
Desde el punto de vista de la semiótica, la cultura es una inteligência colectiva y una memória colectiva, esto es, un mecanismo supraindividual de conservación de ciertos comunicados (textos) y elaboración de otros nuevos". (...) Cada cultura define su paradigma de qué debe recordar (esto es, conservar) y qué se há de olvidar. s palavras do reputado semioticista Iuri Lotman (Rev.
Criterios, 1994), grande estudioso da cultura, inspira 1 retomada de reflexões do roteirista Walter George Durst, um dos grandes nomes da arte de roteirizar no Brasil. Quando este artigo for publicado já terá passado quase uma década de seu falecimento, mas a sua obra permanece, e sem dúvida, cabe ao meio acadêmico resgatá-la numa cultura tão desmemoriada quanto a nossa e sobretudo tratando-se de um meio tão volátil e com uma obsolescência programada tão cruel quanto a televisão, meio para o qual Durst mais trabalhou e está tão fortemente inserido em nossa cultura. A obra do roteirista é certamente un paradigma que se debe conservar.

\section{Pequenas memórias esparsas: depoimentos a Anna Maria Balog ${ }^{1}$}

Tive o privilégio de privar da presença de Walter George Durst quando Docente do Departamento de Cinema, Rádio e

1. Dados recolhidos em (1) ANOTAÇÕES. Curso de roteirização para Cinema e TV. ECAUUSP/CODAC/EMBRAFILME. Org. Anna Maria Balogh, colaboração Vânia Debs. Convidados: Eduardo Escorel; Carlos Lombardi, Jorge Duran, Doc 
Televisão da Escola de Comunicações e Artes da USP. O primeiro contato se deu quando o convidei para o Seminário de Roteirização em Cinema e TV, curso de extensão universitária que organizava e que contou com a presença de célebres profissionais do ramo no Brasil, como Eduardo Escorel, Doc Comparato, Jorge Duran e Carlos Lombardi, entre outros. A conferência de Walter Durst durante o evento foi emblemática no sentido de trazer o melhor da experiência e do conhecimento de um veterano profissional da área com realizações envolvendo os mais diversos veículos, conhecedor de suas diferentes possibilidades e servidões, bem como pela riqueza e pluralidade das ilustrações de trechos de suas obras utilizadas para o melhor entendimento do tema por parte da platéia do auditório Lupe Cotrim na ECA.

Em outro momento, tive a oportunidade de convidá-lo, juntamente com o maestro Júlio Medaglia, para a aula de encerramento de meu curso de Pós da ECA sobre adaptações que, naquele semestre, versava precisamente sobre a transmutaçã̃o de Grande Sertão: Veredas e ambos aceitaram o convite para deleite dos alunos. Foi uma aula verdadeiramente memorável.

Finalmente, quando já na fase de elaboração da tese de livredocência sobre o tema, que depois se transformaria no meu livro Conjunçõe - Disjunções - Transmutações. Da literatura ao Cinema e à $T V$, procurei mais uma vez o renomado roteirista para discutir aspectos da 'grande arte de roteirizar' a transposição de Grande Sertão: Veredas, obra-prima de João Guimarães Rosa, para a minissérie da Globo por ocasião dos vinte anos da emissora, Durst me recebeu em sua casa para várias entrevistas e discussões sempre com inesgotável solicitude.

Ainda hoje lembro com saudade as outras vezes em que topávamos um com o outro na livraria da Edusp, sempre garimpando

Comprarato, Walter George Durst e Antonio Mercado. Abri-Maio 1986. (2) Acervo sonoro da Autora; Anotações. Adaptações fílmicas de obras brasileiras para cinema, televisão e video. ECAUSP. Curso de Pós-Graduação ministrado pela Profa. Dra. Anna Maria Balog, Junho 1988. Aula de encerramento convidados: Walter George Durst e Júlio Medaglia. (3) Anotações. Entrevista. Conversações de Walter George Durst com Anna Maria Balogh sobre a roteirização e elaboração de Grande Sertão: Veredas, acervo sonoro da autora. 
em -meio aos livros tão queridos, lembro-me, ainda de sua figura afastando-se em meio aos gramados do campus com seu indefectível boné...

Além do breve resgate de alguns momentos pertencentes à gaveta de guardados da memória, o objetivo mais importante do artigo é, sem dúvida, o de trazer alguns trechos selecionados das afirmações do autor durante os eventos, entrevistas e contatos mencionados. Acredita-se serem relevantes para interessados na arte de roteirizar e fazèr televisão, bem como na comunicação em geral.

\section{O poder desmesurado da TV brasileira e a roteirização}

A arte e a técnica de escrever textos para cinema, rádio, TV e publicidade, se firmou definitivamente no Brasil como ritmo industrial da televisão, cuja força na cultura brasileira é verdadeiramente excessiva em muitos aspectos, tal como já tiveram ocasião de mencionar os Mattelart em sua obra $O$ Carnaval das Imagens ao falar do

espaço social desmedido que ocupa o dispositivo televisivo num país como o Brasil. Essa competência exorbitante faz com que se possa legitimamente ter a impressão de que um determinado Brasil exige hoje de sua televisão bem mais do que ela pode oferecer estruturalmente...(1989, p.131)

No já mencionado Seminário de Roteirização da ECA/USP, Durst revela um entendimento muito realístico quando perguntado sobre a mesma questão: É uma idéia que a gente tem de que a televisão pode salvar o Brasil com a força que ela tem, não é função dela, viu?

Ainda assim, o roteirista sempre deu o melhor de si em seus trabalhos, alguns polêmicos e vanguardistas, como as novelas Nina 
e Gabriela, e, sobretudo, Grande Sertão Veredas, contribuindo para a excelência da TV brasileira. Em sua longa experiência no métier, Durst trabalhou nos programas TV de Vanguarda transpondo peças de grandes autores teatrais, em Cinema em Casa no qual se apresentavam apresentações radiofônicas de filmes famosos, tais como Roma, cidade aberta, de Roberto Rosselini, entre outros. Neste sentido também Durst deu um singelo depoimento no Seminário de ECA/USP ao lembrar que ele e sua esposa Bárbara Fázio procuravam anotar tudo o que viam ao assistir aos filmes, fazendo canhestramente uma decupagem 'no escurinho do cinema', para depois relembrá-los, procedimento utilizado por muitos cinemaníacos veteranos, antes do advento do vídeo-tape.

O célebre roteirista trabalhou também nas : Redes Bandeirantes, Manchete e Cultura. Ao que parece, no entanto, seus trabalhos mais marcantes se realizaram na Rede Globo e sobretudo no campo das adaptações, motivo pelo qual será a parte da obra de Durst a que se dará maior ênfase no artigo. No formato novelas cabe mencionar Gabriela, adaptada da obra de Jorge Amado, no formato minissérie teríamos Rabo de Saia, Anarquistas, Graças à Deus, Memórias de um Gigolô e Grande Sertão: Veredas, o mais memorável de todos. Já no fim de sua vida, com uma equipe de co-roteiristas, Durst supervisionou e realizou a novela adaptada Os Ossos do Barão, para o SBT, a partir de um conjunto de obras de Jorge de Andráde, parte das quais já havia sido adaptada no passado por outras emissoras.

\section{A grande arte de se transpor Grande Sertão: Veredas para a TV}

Algumas das principais declarações relativas às questões surgidas durante a roteirização do romance de Guimarães Rosa estão detalhadas em Conjunções-Disjunções -Transmutações. Dá Literatura ao Cinema e à TV. Apenas a guisa de lembrete, podem ser mencionados os principais desafios enfrentados pelo roteirista nesta árdua tarefa. 
Literatura: arte solitária - TV: arte de equipe

Quando o escritor elabora seu discurso, ele se encontra só, no máximo com a companhia de seus fantasmagóricos personagens fictícios e suas próprias decisões no tocante aos modos de plasmar a ficção. No caso do cinema e da TV, temos artes de equipe. O roteiro, que se é adaptado deve guiar-se, ao menos em parte pela obra original, passará nas mãos do diretor, do diretor de fotografia, dos atores, do figurinista, do cenógrafo, do editor de imagens etc.,etc.,etc...

O conteúdo passa pela visão de inúmeros profissionais, especialistas em métiers diversos e com visões também diversas, por vezes conflitantes do mesmo fazer artístico.

No tocante a algumas das estratégias de enunciação roseanas presentes no romance, Durst considerava ser impossível transpor para a TV a estrutura conversacional utilizada por Guimarães Rosa e a narrativa em primeira pessoa, em sua opinião seriam muito tediosas principalmente levando-se em conta a longa extensão das minisséries brasileiras se comparadas às estrangeiras. No roteiro da minissérie, minuciosamente analisada para a elaboração do livro, nota-se que o roteirista não inseriu nenhum narrador. No roteiro final, no entanto, foi depois acrescentada por Avancini um narrador na voz de Mário Lago, o compadre Quelemém, estratégia da qual o roteirista adaptador discordava, conforme revelam suas palavras em uma das entrevistas citadas:

Quelemén é apenas um dos pólos referenciais do Riobaldo, pólo mais místico, confessional (...) Avancini ficou com medo de desaparecer o interlocutor, foi o último medo do Avancini, deu para o José Antonio de Souza que acrescentou a voz 'off'. É também uma coisa na qual eu não acredito, não atrapalhou, mas não acrescentou em nada....Avancini pensou de outro modo, talvez ele tenha razão, não sei.

Outro elemento que mostra o quanto é difícil a arte de trabalhar em equipe se refere à escalação de Diadorim. A escolha 
que prevaleceu determinou inúmeras diferenças entre o original (o livro), os primeiros tratamentos do roteiro e o roteiro final no tocante às estratégias de enunciação. Durst era contrário à escalação de um ator conhecido para viver Diadorim. Durante a Aula de Pós mencionada, o adaptador revelou que foram cogitadas muitas possibilidades no tocante ao papel, conservar o mistério de sua feminilidade, escalar uma atriz desconhecida, escalar irmãos gêmeo, mas foi voto vencido pois o diretor Walter Avancini tinha Bruna Lombardi em mente desde o começo, neste sentido as divisões do universo cognitivo original são subvertidas na adaptação e perdese o tom de nostalgia e arrependimento do fluir narrativo do Riobaldo literário. Não fosse a maestria do roteirista, teríamos um Riobaldo um tanto parvo não percebendo o que o espectador sabe desde o começo: trata-se de uma mulher. Perde-se aí também na transposição televisual a grande revelação que ocorre só quase.ao final do romance, a verdadeira identidade de Diadorim, cujo caráter folhetinesco seria para Durst perfeitamente adequado ao melodrama televisual.

Os exemplos citados nos dão uma idéia do quanto é difícil a realização de um trabalho em equipe, dificultado ainda mais neste caso pelo enorme porte da produção, francamente hollywoodiana para a época, o prestígio irrefutável da obra original e vários outros. Ainda assim, o roteirista-adaptador se revela um otimista em relação ao meio e um gentleman em relação aos seus parceiros de equipe,mesmo reconhecendo algumas das limitações do veículo televisão, ao discutí-lo em comparação ao cinema com um aluno da platéia, Durst manifesta seu justificado orgulho e modéstia no tocante a Grande Sertão: Veredas, na afirmação que segue:

Eu posso discordar de algumas coisas do Grande Sertão, mas eu não posso negar e acho que nenhum de vocês negaria que, como direção, do Avancini - posso falar porque ele não está aqui - é uma direção portentosa. Para a televisão nunca ninguém fez aquilo, com os recursos e condições da televisão. Estou falando sobre a forma, não o conteúdo, onde eu entraria. 
Em relação ao conteúdo, Durst conservou com maestria os principais conceitos de Grande Sertão, sobre a vida, o amor, a amizade, a morte, o sertão, considerados como um verdadeiro manual do viver por Durst e sempre colocados por ele na boca do personagem adequado e no momento narrativo mais pertinente da minissérie, como as observações sobre a morte na boca de Bigri antes de sua própria passagem para a outra vida, entre vários exemplos possíveis.

Em suma, estas breves recolecções podem atestar a enorme quantidade de desafios que as estratégias de enunciação e transmutação para minissérie de uma obra-prima desta envergadura representaram para o renomado roteirista e toda a equipe encarregada a realização da minissérie.

\section{Tenacidade e roteirização? O princípio da contradição}

Cabe, ainda, retomar a tocante tenacidade do roteirista $\mathrm{e}$ a sua firme crença na possibilidade, que muitos julgavam impensável, de transpor uma obra deste porte para a TV.

Durst afirma no Seminário que a obra prima de Guimarães Rosa é escandalosamente desconhecida do proprio brasileiro, mas que estava decidido a levá-lo à televisão, convencer o meio de comunicação que um romance tão desafiador pudesse ir ao ar lhe custou anos de insistência e uma noção do que ele mesmo denominou de 'princípio da contradição', que corresponderia grosso modo, àquela brecha oportuna, aquele momento de subversão do sistema, que o próprio sistema abre excepcionalmente. Durst explica que a Globo durante um bom tempo priorizou a questão da audiênçia para não perder a liderança para o.SBT que a ameaçava e somente quando comemorava 20 anos é que a questão do prestígio passou a ser prioritária. Quer prestígio, eu disse (Durst), é Guimarães Rosa. Isso é o que eu chamo de aproveitar uma contradição. O roteirista aconselha ainda aos alunos que procurem conhecer o melhor possível a 
televisão tal qual ela é, para depois poderem fazer a televisão que querem, que sonham, quando puderem aproveitar o princípio da contradição.

Outra das grandes satisfações de Durst revela da na Aula de Pós, em relação à transposição desta obra-prima é o fato de que, após a veiculação da minissérie ele teria constatado pela leitura das revistas Veja e Istoé da época que o romance de Guimarães Rosa havia entrado no quinto lugar da lista de mais vendidos.

\section{Conta de somar ou subtrair: adaptações e extensão das obras}

Outro elemento que preocupava bastante o roteiristaadaptador era a questão do conjunto de idéias que a obra original pudesse aportar ao adàtador, posto que em sua opinião, a maioria de nossos autores era mais talhado para ser contista, cronista, em suma, eram muito econômicos em termos de idéias, tramas e temas, o que dificultava sobremaneira a transposição ao televisual, longo e caudaloso, assim, para ele

o livro tem 200 a 300 páginas, uma novela, especialmente a das seis, que recorreu muito à adaptação, tem 500 páginas em medi, em média. $O$ adaptador se esforça num trabalho de transe para se aproximar do autor, se for vivo, falar com ele; Jorge Amado é generoso, mas no geral dá problema.

Neste sentido, cabe lembrar que o formato de minissérie parece o ideal e o mais próximo à extensão dos grandes romances que se transpõem à TV, sobretudo nos momentos festivos: Ainda que as páginas do roteiro e do romance tenham características próprias, a extensão do romance roseano e do roteiro de Durst é muito similar. Em compensação, o roteirista afirmou que foram necessários acréscimos e a criação de tramas paralelas no caso de Rabo de Saia, 'de Condé, bem como de Memórias de um Gigolô, 
de Marcos Rey, com o qual Durst trabalhou em parceria nesta última transposição, Trata-se de um romance breve com uma estrutura verdadeiramente minimalista versando sobre uma prostituta dos anos vinte, Lu, vivida por Bruna Lombardi, cujas atenções são disputadas por doị gigolôs, Mariano e Esmeraldo, gerando disputas, traições, artimanhas as mais diversaș.

Cabe lembrar, finalmente, que nestas relações de equipe, na opinião de Doc Comparato (Seminário), o tripé roteiristadiretor-produtor costuma responder pelas relações mais delicadas, polêmicas e potencialmente explosivas do fazer fílmico e do fazer televisual. Desta forma, na televisão - se manifesta uma certa tendência a reiterar parcerias que funcionam apesar das diversidades de opinião, tanto é assim que Avancini e Durst trabalharam juntos em várias obras sendo a novela mais famosa Gabriela e a minissérie Grande Sertão: Veredas.

Em termos temáticos, muitas das personagens se coadunam com as idéias de esquerda do roteirista, como a professora vanguardista da novela Nina, a rebelde Malvina de Gabriela, Mundinho Falcão se apresentou como um renovador possível na mesma novela, mas é absorvido pelo sistema ao final, assim como Riobaldo se aburguesa na opinião de Durst (Entrevista) junto a Otacília no final de Grande Sertão.

Cabe observar ainda, que Durst foi um inovador, talvez até malgré soi, em sua derradeira adaptação: muito embora se tratasse de uma novela Os ossos do Barão, da SBT, terminou indo ao ar já como obra terminada qual uma minissérie causando estranheza em alguns membros mais jovens do elenco. Além disso, como já se teve ocasião de observar na segunda edição de Conjunções.... a novela faz parte de uma nova tendência em termos de transposições em que a obra do autor, no caso Jorge de Andrade é considerada no seu conjunto e partes de outras obras se inserem na obra central numa estratégia de enunciação de cunho mosaical, que oferece maior liberdade ao roteirista-adaptador para fazer suas escolhas e composições: Os ossos do Barão, Ninho da Serpente e A Escada. 


\section{O que é afinal a grande arte de roteirizar?}

Perguntado no Seminário sobre a sua definição da arte de roteirizar, Durst se revelou lapidar e sintético: a partir de uma frase de Ionesco definiu roteiro como uma arquitetura de antagonismos: os ramiros vs. os hermógenes, coronel Tonico Bastos vs. Mundinho Falcão, os Ghirotto vs. os Taques Redon.... e eis que a partir deste estratagema básico a narrativa deslancha e encanta os telespectadores.

Finalmente, como profissional experiente que já havia atuado e feitos transposições nos mais diversos veículos, Durst respondeu a questões dos alunos no Seminário sobre o tema.

\section{Questões sobre cinema e televisão}

Sobre as diferenças entre o cinema e a televisão Durst comenta que não é possível comparar uma empresa de cinema com uma de TV. O ritmo de produção da TV é muito mais industrial posto que num formato como a novela é necessário fazer 30 a 40 cenas em média para se garantir os capítulos seguidos no ar. A televisão tem mais repetições, mais cenas longas para preencher este espaço, enquanto que o cinema seria o mais dinâmico dois meios, não se deteria muito tempo em esclarecimentos, explicações ou repetições. Para Durst o cinema é movimento e em termos de recursos, movimento sempre significa dinheiro, bastante dinheiro.

Walter George Durst menciona, ainda que é possível se fazer boas obras dentro dos limites impostos pela televisão e cita a novela Roda de Fogo, de Lauro César Muniz, que considera muito bela do ponto de vista formal ainda que as cenas tenham um ritmo lento mais tendente ao teatral, observam-se bem as alternâncias entre o dia e a noite, há um esmero nos aspectos formais. Tal como Durst, os críticos de TV da época também mencionaram o preciosismo formal da novela, sobretudo o tratamento de luz em relação aos ambientes em que circulava Tarcísio Meira, o protagnonista, cuja doença era realçada muitas vezes pelo uso de luzes em tons sombrios, azulados. 
Durst se refere em inúmeras ocasiões ao jogo bruto da televisão tendo em mente as servidões impostas à linguagem audiovisual por um veiculo tão poderoso quanto presente. Dá um exemplo à platéia citando dois cineastas, Bergman e Fassbinder:

O Ingmar Bergman fez Cenas de um Casamento, e o Fassbinder, que, na verdade é o Ingmar Bergman moderno, com a vantagem que nem precisa de diálogo, tem muito mais imagem que diálogo, também ele fez uns especiais para a televisão que estão passando agora na TV Cultura. Quer dizer, a fita Cenas de um Casamento é enxundiosa, repetitiva, eles dizem e repetem: é "gorda", uma coisa que Ingmar Bergman nunca faria. No trabalho de Fassbinder tem até voz em off dizendo o que já está na imagem. Então você tem que aceitar que tem uma coisa na natureza da televisão, o medo de que se uma coisa não for compreendida, já dá ruído...nesse jogo violento da televisão no sentido de segurar a audiência. $O$ script de cinema não é tão violento, nem o script de teatro.

\section{Bibliografia}

ADAMI, A. et al. 2002. Mídia, Cultura, Comunicação. São Paulo: Arte e Ciência.

. 2003. O cinema em Casa: Uma Era do Rádio. In, ADAMI et al. Mídia, Cultura, Comunicação.2, São Paulo: Arte e Ciência, 203.

BALOGH, A. M. 2002. O Discurso Ficcional na TV. São Paulo: EDUSP.

2005. Conjunções, Disjunções, Transmutações. Da Literatura ao Cinema e à TV. São Paulo: Annablume, $2^{a}$. Edição revisada e aumentada.

MORAIS, O. 2000. Grande Sertão: Veredas. O Romance Transformado: São Paulo: Edusp/Fapesp.

FORNET, A. 1987. El guionista y su oficio. La Habana. Escuela Internacional de Cine y Televisión de San Antonio. 